\title{
ANALISIS PENCEMARAN GAS SO2 DARI PEMBAKARAN BRIKET TANDAN KOSONG SAWIT DENGAN VARIASI VENTILASI DAPUR
}

\author{
Hafidawati $^{1)^{*}}$, Elvi Yenie ${ }^{2)}$, Yoana ${ }^{3)}$ \\ ${ }^{1,2,3}$ Program Studi Teknik Lingkungan, Universitas Riau, HR Subrantas KM 12,5, Pekanbaru,Indonesia. \\ Hafidawati@lecturer.unri.ac.id*; elviyennie@lecturer.unri.ac.id; eviayohana10@gmail.com
}

\begin{abstract}
ABSTRAK
Tandan kosong sawit (TKS) sebagai salah satu limbah padat hasil pengolahan tandan buah segar kelapa sawit, yang memiliki potensi sebagai sumber energi alternatif yaitu sebagai briket biomasa, dengan karakteristik memiliki energi panas $20.093 \mathrm{~kg} / \mathrm{kJ}$ dan energi kalor sebesar $5.698 \mathrm{kal} / \mathrm{gr}$. Dalam pemanfaatannya, briket ini dapat berdampak pada kualitas udara dalam ruangan, salah satunya adalah karena gas SO2 yang diemisikan selama pembakaran briket TKS ini. Tujuan dari penelitian ini adalah menentukan besarnya konsentrasi gas SO2 di ruangan dapur selama pembakaran briket dan melakukan pengendalian pada kondisi pengukuran yang melebihi Baku Mutu Kualitas Udara Ambien. Pengambilan sampel menggunakan alat impinger pada ruangan yang memiliki ventilasi sebesar 5\% dari luas lantai ruangan dapur dan kemudian sampel dianalisis dengan menggunakan AAS. Hasil pengukuran diketahui besarnya konsentrasi gas SO2 sebesar 0,16 ppm yang melebihi baku mutu dari PerMen Kes 1077/2011 (0.1 ppm), sehingga perlu dilakukan pengendalian untuk mengurangi emisi yang dihasilkan. Pengendalian yang dilakukan adalah mengatur bukaan ventilasi yaitu pada ventilasi $10 \%$ (sesuai standar penyehatan ruangan dari PerMen Kes 1077 tahun 2011) dan pada ventilasi 15\%. Diperoleh hasil pada ventilasi $10 \%$ sebesar $0,106 \mathrm{ppm} \mathrm{SO}_{2}$ dan pada ventilasi $15 \%$ terukur $0,09 \mathrm{ppm} \mathrm{SO}_{2}$. Berdasarkan hasil ini dapat dinyatakan bahwa pembakaran briket tandan kosong sawit dengan kondisi pembakaran pada bukaan ventilasi $15 \%$, aman digunakan sebagai bahan bakar alternatif dalam skala rumah tangga.
\end{abstract}

Kata kunci: Briket TKS, Energi terbarukan, Gas SO2, Pencemaran Udara, Ventilasi udara dapur

\section{ABSTRACT}

Oil palm empty fruit bunches (TKS) as one of the solid wastes from the processing of oil palm fresh fruit bunches, which have the potential as an alternative energy source, namely as biomass briquettes, with the characteristics of having heat energy of $20,093 \mathrm{~kg} / \mathrm{kJ}$ and heat energy of $5,698 \mathrm{cal} / \mathrm{gr}$. In its utilization, these briquettes can have an impact on indoor air quality, one of which is the presence of $\mathrm{SO} 2$ gas produced during the combustion of these briquettes. The purpose of this research is to determine the concentration of SO2 gas in the kitchen during briquette combustion and to control the measurement conditions that exceed the Air Quality Standards. Sampling using the impinger tool in a room that has ventilation of $5 \%$ of the floor area of the kitchen and then the sample is analyzed using AAS. The measurement results show that the concentration of SO2 gas is $0.16 \mathrm{ppm}$, which exceeds the quality standard of Minister of Health Regulation 1077/2011 (0.1 ppm), so it is necessary to control it to reduce the resulting emissions. The control carried out is to adjust the ventilation openings, namely at $10 \%$ ventilation (according to room sanitation standards from PerMen Kes 1077 of 2011) and $15 \%$ ventilation. The results obtained at $10 \%$ ventilation of $0.106 \mathrm{ppm} \mathrm{SO} 2$ and at $15 \%$ ventilation measured $0.09 \mathrm{ppm} \mathrm{SO}$. The results of this measurement are compared with the $\mathrm{SO}_{2}$ quality standard regulated in the Regulation of the Minister of Health of the Republic of Indonesia No. 1077 of 2011, where the quality standard for $\mathrm{SO}_{2}$ is $0.1 \mathrm{ppm}$. Based on these results, it can be stated that the burning of empty palm fruit bunches briquettes with burning conditions at $15 \%$ ventilation openings is safe to use as an alternative fuel on a household scale.bstrak ditulis dalam bahasa Inggris yang berisikan latar belakang umum, tujuan penelitian, metode/pendekatan penelitian,hasil penelitian dan kesimpulan/saran. Abstrak ditulis dalam satu alenia, tidak lebih dari 200 kata. Bahasa penulisan sesuai tata bahasa Inggris

Keywords: Briquete TKS, Renewable Energy, Gas $\mathrm{SO}_{2}$, Air Pollution, Ventilation 
Diunggah November 2021, direvisi: Desember 2021, diterima: Desember 2021, dipublikasi: 31Desember 2021

Copyright (c) 2021 Hafidawati, Elvi Yenie, Yoana

This is an open access article under the CC-BY license

\section{PENDAHULUAN [TNR 12 Spasi 1]}

Industri pengolahan kelapa sawit menghasilkan limbah dari aktifitas produksinya yaitu berupa limbah padat dan limbah cair. Limbah padat yang dihasilkan diantaranya adalah cangkang kelapa sawit, serat (fiber) dan Tandan Kosong Sawit (TKS). Diantara limbah tersebut, TKS merupakan limbah yang terbanyak dihasilkan yaitu sekitar 23\% dari keseluruan pengolahan tandan buah segar (TBS) (Khoiri dkk, 2013). Limbah TKS masih belum dimanfaatkan secara optimal di industri pengolahan sawit, yang saat ini digunakan hanya sebagai penimbun jalan kebun. Hal ini dapat menimbulkan pengaruh terhadap lingkungan berupa bau yang tidak sedap pada musim penghujan dan mendatangkan lalat dalam jumlah yang banyak serta memerlukan waktu $3-4$ bulan untuk penguraian dan juga akan mengakibatkan polusi udara pada saat dilakukan pembakaran dari limbah yang menumpuk di pabrik (Ullyta, dkk, 2017).

Untuk mengurangi masalah yang ditimbulkan dari penumpukan Tandan Kosong Sawit, salah satunya adalah dengan memanfaatkan sebagai bahan bakar alternatif yaitu berupa briket. Briket didefinisikan sebagai bahan bakar yang berwujud padat dan berasal dari sisa-sisa organik yang telah mengalami proses pemampatan dengan daya tekan tertentu (Yudanto dan Kusumaningrum, 2008).

Potensi TKS sebagai sumber energi briket dapat dilihat dari nilai energi panas yang mencapai $20.093 \mathrm{~kJ} / \mathrm{kg}$ (Mardiansyah,2015) dan nilai kalor sebesar $5.698 \mathrm{kal} / \mathrm{g}$. Briket ini dapat dimanfaatkan oleh masyarakat yang masih menggunakan minyak tanah atau kayu bakar sebagai sumber bahan bakar di rumah tangga tradisional atau di industi pengasapan. Hal ini diakibatkan karena keberadaan minyak tanah sudah sulit ditemui dan harganya yang semakin mahal.

Pemanfaatan energi terbarukan (renewable energy), akan meningkatkan jumlah pencemar di atmosfer yang mengandung debu, gas-gas seperti Sulfur dioksida (SO2), Nitrogen oksida (NOx), Carbon Monoksida (CO), Asam hydroklorik dan logam-logam. Keberadaan polutan dari pembakaran batubara akan menyebabkan polusi udara. Polusi udara adalah terkontaminasinya udara oleh bahan berbahaya yang karena jumlah ataupun karakteristiknya dapat membahayakan kesehatan manusia dan/atau lingkungan sekitar. Gas rumah kaca akan sangat berbahaya karena dapat bereaksi dengan radikal bebas di udara membentuk asam yang dapat menyebabkan terjadinya hujan asam dan penipisan lapisan ozon (Ony,2018).

Proses pembakaran biomassa akan menghasilkan gas Sulfur dioksida $\left(\mathrm{SO}_{2}\right)$ dan sebagian kecil menjadi Sulfur trioksida $\left(\mathrm{SO}_{3}\right)$. Kandungan Sulfur Oksida yang diemisikan dari pembakaran biomassa dapat menyebabkan iritasi pada alat pernapasan manusia, mengurangi jarak pandang, sekresi muskus berlebihan, sesak napas, dan lebih lanjut dapat menyebabkan kematian. Reaksi sulfur oksida dengan air hujan, dapat menimbulkan hujan asam yang sangat berbahaya bagi tanaman, hewan terutama hewan air, serta sifatnya yang korosif dapat merusak infrastruktur-infrastruktur (April,2013).

Seperti halnya pembakaran biomassa yang dapat memberikan dampak, pemanfaatan briket sebagai bahan bakar juga dapat mempengaruhi kualitas udara dalam ruangan. Hal ini disebabkan karena pembakaran briket dapat menghasilkan pencemar gas salah satunya adalah gas $\mathrm{SO}_{2}$. Gas tersebut jika terhirup dan masuk ke dalam tubuh dalam jumlah yang melebihi baku mutu akan memberikan dampak terhadap kesehatan, oleh karena itu perlu diketahui kualitas briket TKS ini sebagai sumber energi terbarukan yang ramah lingkungan. Untuk mengetahui kualitas udara dari emisi pembakaran briket, maka dilakukan uji kualitas udara dari pembakaran briket tandan kosong sawit. Sehingga bisa ditetapkan apakah briket 
dari tandan kosong sawit ini adalah sumber energi alternatif yang aman digunakan dalam skala rumah tangga.

\section{METODE}

\section{Alat dan Bahan}

Pembuatan briket dari Tandan Kosong sawit menggunakan beberapa peralatan yaitu ayakan berukuran 120 mesh, dan alat press briket. Uji coba pembakaran menngunakan kompor briket, seperti terlihat pada Gambar 1. dan pengujiannya emisi yang dihasilkan dengan menggunakan instrumen impinger, stopwatch, dan instrumen spektrofotometer uvvis. Pengujian dilakukan di sebuah ruang dapur artificial.

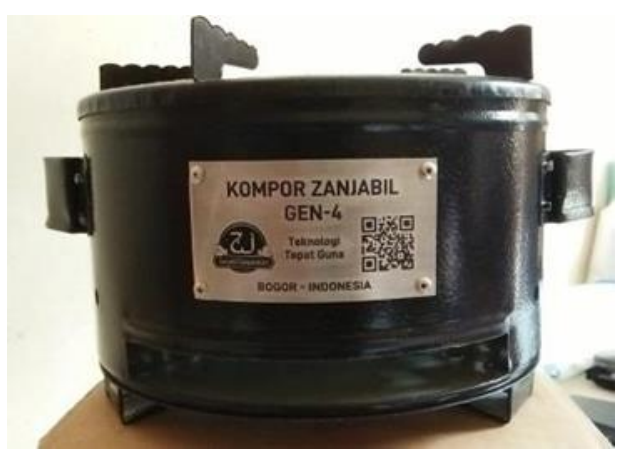

\section{Gambar 1. Kompor Biomassa Pembakaran Briket TKS}

Bahan yang digunakan pada penelitian ini adalah Tandan Kosong Sawit dan perekat tapioka sebagai bahan pembuatan briket, larutan penjerap $\mathrm{SO}_{2}$

\section{Prosedur Penelitian}

Tahapan pengujian emisi dilakukan mengikuti tahapan pada Diagram alir penelitian dapat dilihat pada Gambar 2. Sebelum dilakukan pengambilan sampel gas $\mathrm{SO}_{2}$ dari pembakaran briket, terlebih dahulu dilakukan pembuatan briket TKS. Pembuatan briket dilakukan dengan proses karbonisasi Tandan Kosong Sawit dalam furnance pada suhu 450 ${ }^{\circ} \mathrm{C}$ selama 90 menit. Kemudian dihaluskan dan disaring dengan ayakan berukuran 120 mesh.

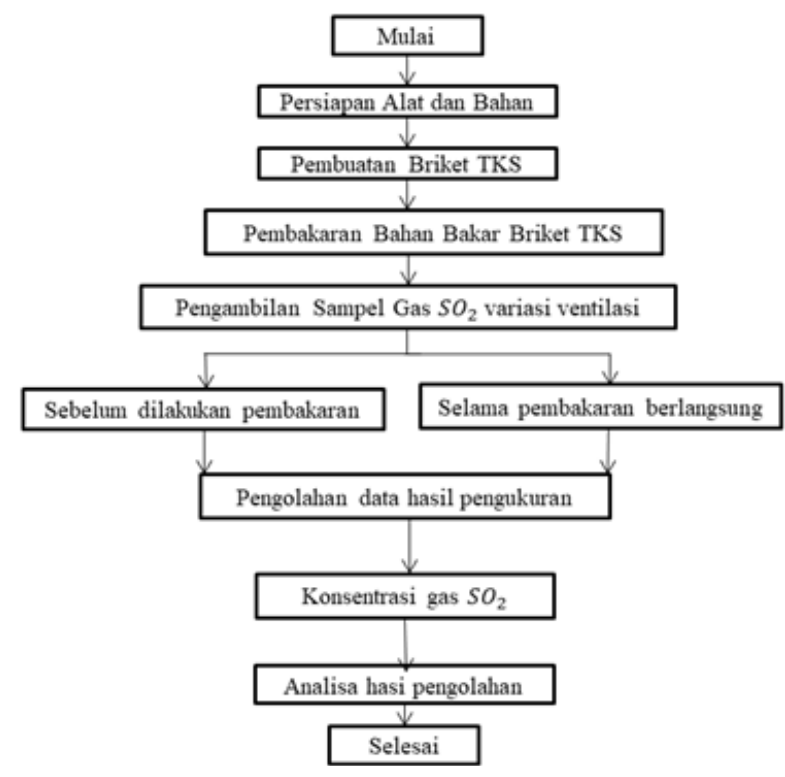

Gambar 2. Tahapan Prosedur Penelitian 


\section{Prosedur Pembuatan Briket}

Prosedur pembuatan briket dan kondisi optimal briket mengacu kepada hasil penelitian Ronaldo (2020) tentang karakteristik briket TKS. Pencampuran dengan perekat tapioka memiliki perbandingan tepung tapioka dengan air yaitu 1:10 dan konsentrasi perekat yang dicampurkan sebanyak 4\% dari berat total bahan baku kemudian ditekan dengan tekanan 120 bar.

\section{Prosedur Pengambilan Data Background}

Tujuan dilakukannya pengambilan data background adalah sebagai tahap pengujian awal untuk mengetahui kondisi awal dan gambaran tentang kualitas udara dalam ruangan sebelum dilakukannya pembakaran. Pengujian untuk data background pada penelitian ini dilakukan selama 1 jam

\section{Prosedur Pengambilan Sampel Gas $\mathrm{SO}_{2}$ dalam Ruangan}

Pengambilan sampel dilakukan terhadap pembakaran briket Tanda Kosong Sawit dengan menggnakan kompor biomassa. Kompor biomassa yang digunakan untuk pembakaran briket Tanda Kosong Sawit dengan dimensi tinggi $12 \mathrm{~cm}$, diameter $20 \mathrm{~cm}$ dengan tinggi ruang bakar $6,7 \mathrm{~cm}$ serta diameter ruang bakar $15,8 \mathrm{~cm}$. Pembakaran menggunakan briket yang dimasukkan ke dalam ruang bakar sebanyak 2/3 ruang bakar atau sebanyak lebih kurang 140gram briket Tanda Kosong Sawit yang akan dibakar. Proses pembakaran briket dalam proses memasak air untuk mendapatkan data konsentrasi emisi gas $\mathrm{SO}_{2}$. Tahapannya dapat dilihat pada Gambar 3 berikut.

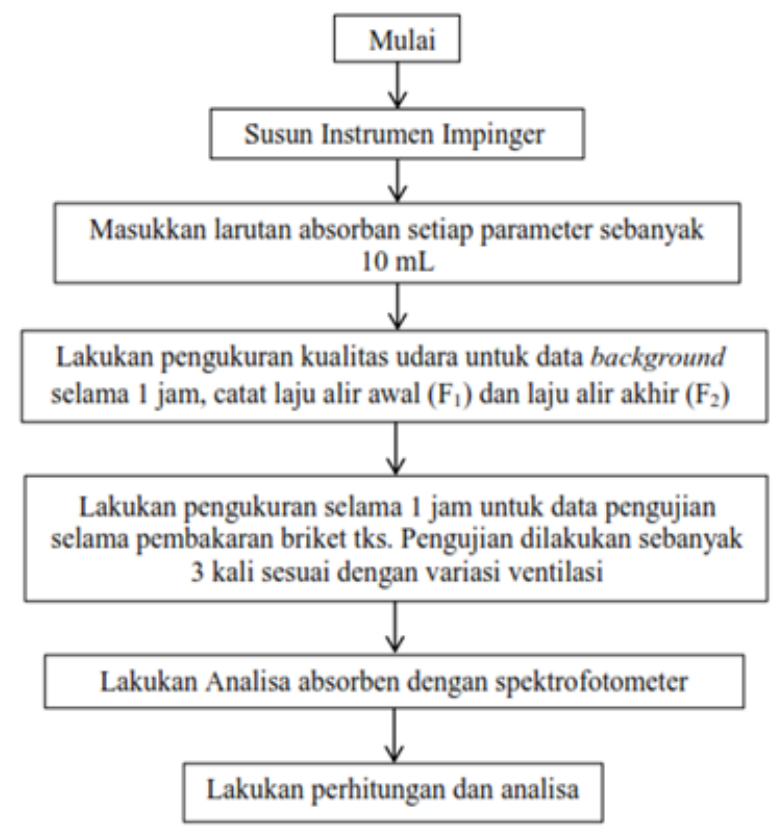

\section{Gambar 3. Tahapan Sampling dan Pengujian Gas SO2 dari Pembakaran Briket Tanda Kosong Sawit,}

Pengambilan sampel gas SO2 dilakukan dengan pengambilan sampel selama 1 jam dalam dapur yang berdimensi panjang $2 \mathrm{~m}$, lebar $1 \mathrm{~m}$, tinggi $2,6 \mathrm{~m}$, dengan variasi ventilasi dapur 5\%, 10\% dan 15\% dari luas lantai dapur. Pengambilan sampel menggunakan instrument impinger. Pengujian sampel gas berdasarkan SNI 19-7119.7-2005 tentang Cara Uji Kadar Sulfur Dioksida $\left(\mathrm{SO}_{2}\right)$ dengan Metode Pararosanilin menggunakan 
Spektrofotometer. Kemudian hasil pengukuran akan bandingkan dengan Peraturan Menteri Kesehatan RI No. 1077 Tahun 2011 tentang Pedoman Penyehatan Udara dalam Ruangan, Pengambilan sampel gas SO2 menggunakan impinger akan dilakukan selama 1 jam dengan satuan konsentrasi $\mu \mathrm{g} / \mathrm{m} 3$. Sehingga perlu dilakukannya konversi satuan konsentrasi dalam ppm dan konversi waktu paparan selama 24 jam. Untuk konversi satuan konsentrasi $\mu \mathrm{g} / \mathrm{m} 3$ ke ppm menggunakan rumus berikut ini (Boguski, 2019):

Dimana:

$$
\text { ppm }=\left(\frac{24,45 \times \text { Konsentrasi } \mu \mathrm{g} / \mathrm{m}^{3}}{\text { berat molekul }}\right) \times 10^{-3}
$$

Berat molekul $\mathrm{SO}_{2}=64,066$

Kemudian untuk konversi waktu paparan menggunakan rumus Canter berikut ini.

Dimana:

$$
\mathrm{C}_{\mathrm{n}}=C_{\text {sampling }} \times\left[\frac{t_{\text {sampling }}}{t_{n}}\right]^{p}
$$

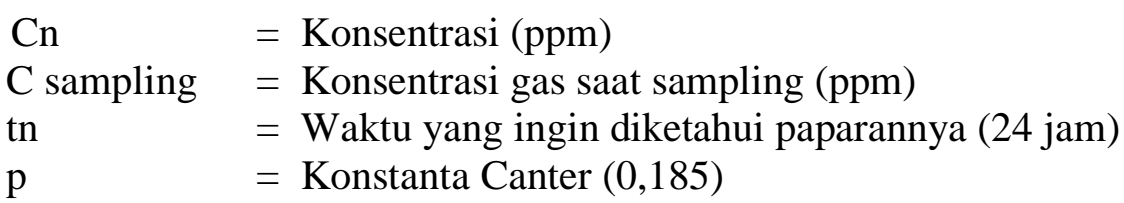

\section{HASIL DAN PEMBAHASAN \\ Pengujian dan Background}

Pengujian background pada penelitian ini dilakukan selama 1 jam. Pengambilan sampel ini diambil sebelum dilakukan nya pembakaran briket. Pengujian ini dilakukan untuk mengetahui kondisi awal dan gambaran tentang kualitas udara dalam ruangan sebelum dilakukannya pembakaran. Data background juga dapat digunakan sebagai acuan/standar untuk bahan pembanding atau evaluasi dari kualitas udara ruangan sebelum dilakukannya perubahan yang diakibatkan dari pembakaran briket tandan kosong sawit (Hadi dan Nurjaman, 2017). Pengambilan sampel pencemar gas $\mathrm{SO}_{2}$ untuk data background diperoleh hasil konsentrasi $\mathrm{SO}_{2}$ sebesar $3,64 \mu \mathrm{g} / \mathrm{m}^{3}(\mathbf{0 , 0 4 4} \mathbf{p p m})$. Kemudian dilakukan juga perhitungan konversi waktu untuk kondisi paparan sesuai PerMenKes No.1077 tahun 2011 dimana waktu paparan $\mathrm{SO}_{2}$ adalah selama 24 jam. Berikut merupakan perhitungan konversi waktu paparan $\mathrm{SO}_{2}$ untuk data background.

$$
\begin{aligned}
\mathrm{C}_{\mathrm{n}} & =C_{\text {sampling }} \times\left[\frac{t_{\text {sampling }}}{t_{n}}\right]^{p} \\
\mathrm{C}_{\mathrm{n}} & =0,044 \mathrm{ppm} \times\left[\frac{1 \mathrm{jam}}{24 \mathrm{jam}}\right]^{0,185} \\
& =0,024 \mathrm{ppm}
\end{aligned}
$$

Hasil pengujian $\mathrm{SO}_{2}$ untuk data background adalah sebesar $0,024 \mathrm{ppm}$, dimana konsentasi ini berada di bawah standar baku mutu. Adanya kandungan $\mathrm{SO}_{2}$ pada kondisi background diperkirakan dari sumber lain dari luar dapur yang masuk melalui ventilasi dapur tersebut..

\section{Pengujian Gas $\mathrm{SO}_{2}$ pada Briket Tandan Kosong Sawit Saat Pembakaran}

Hasil pengukuran dan pengujian konsentrasi gas $\mathrm{SO}_{2}$ selama 1 jam diperoleh hasil sebesar $441 \mu \mathrm{g} / \mathrm{m} 3 \quad \mathrm{SO}_{2} \quad(0,16 \mathrm{ppm})$ selama pembakaran briketTandan Kosong Sawit. Kemudian dilakukan juga perhitungan konversi waktu untuk kondisi paparan sesuai PerMenKes No.1077 tahun 2011 dimana waktu paparan $\mathrm{SO}_{2}$ adalah selama 24 jam. Berikut merupakan salah satu perhitungan konversi waktu paparan $\mathrm{SO}_{2}$. 


$$
\begin{aligned}
\mathrm{C}_{\mathrm{n}} & =C_{\text {sampling }} \times\left[\frac{t_{\text {sampling }}}{t_{n}}\right]^{p} \\
\mathrm{C}_{\mathrm{n}} & =0,16 \mathrm{ppm} \times\left[\frac{1 \mathrm{jam}}{24 \mathrm{jam}}\right]^{0,185} \\
& =0,09 \mathrm{ppm}
\end{aligned}
$$

Dari hasil pegujian didapat adanya 0,09 ppm kandungan $\mathrm{SO}_{2}$ untuk paparan 24 jam. Hal ini berarti kandungan $\mathrm{SO}_{2}$ berada di bawah standar baku mutu PerMenKes RI No. 1077 tahun 2011 tentang Pedoman Penyehatan Udara dalam Ruangan dimana batas kandungan $\mathrm{SO}_{2}$ adalah sebesar 0,1 ppm dengan waktu paparan selama 24 jam. Sehingga pembakaran Briket Tandan Kosong Sawit dengan kondisi luasan ventilasi sebesar $15 \%$ dari luas permukaan lantai ruangan tersebut aman digunakan sebagai bahan bakar alternatif skala rumah tangga.

Pengujian dari pembakaran briket tandan kosong dilakukan didalam ruangan yang memiliki variasi ventilasi 5\%,10\%, dan $15 \%$ dari luas permukaan lantai. Pengujian data hasil pembakaran dilakukan pada dapur yang memiliki dimensi panjang $2 \mathrm{~m}$, lebar $1 \mathrm{~m}$, tinggi 2,6 $\mathrm{m}$ dan menggunakan kompor briket dengan tinggi ruang bakar $6,7 \mathrm{~cm}$ dan diameter ruang bakar 15,8 cm. Briket disusun di dalam kompor dengan 2/3 dari ketinggian ruang bakar kompor (Geombira dkk, 2019) dengan massa 140 gr sekali pembakaran. Pengambilan sampel gas $\mathrm{CO}, \mathrm{SO}_{2}$ untuk masing-masing variasi vetilasi dapat dilihat pada Tabel 1

Tabel 1.. Hasil Sampling Gas $\mathrm{SO}_{2}$

\begin{tabular}{l|l|l|l}
\hline Konsentrasi & \multicolumn{3}{|c}{ Variasi } \\
\cline { 2 - 4 } $\mathrm{Gas} \mathrm{SO}_{2}$ & $5 \%$ & $10 \%$ & $15 \%$ \\
\hline$\left(\mu \mathrm{g} / \mathrm{m}^{3}\right)$ & 781 & 502 & 441 \\
\hline$(\mathrm{ppm})$ & 0.16 & 0.106 & 0.09 \\
\hline
\end{tabular}

Berdasarkan Tabel 1 dapat diketahui bahwa konsentrasi $\mathrm{SO}_{2}$ bervariasi pada setiap variasi luasan ventilasi ruang dapur. Diperoleh hasil bahwa nilai konsentrasi $\mathrm{SO}_{2}$ juga bervariasi dan konsentrasi terendah diketahui pada bukaan ventilasi terbesar yaitu $15 \%$ dari luas ruangan dapur yaitu sebesar $0.09 \mathrm{ppm}$. Jika dibandingkan dengan Baku Mutu pada PerMemKes No.1077 Tahun 2011 sebesar 0.1 ppm terlihat bahwa konsentrasi Gas $\mathrm{SO}_{2}$ pada bukaan 5\% dan 10\% melebihi Baku Mutu, sedangkan untuk variasi $15 \%$ konsentrasi $\mathrm{SO}_{2}$ berada di bawah Baku Mutu. Perbandingan nilai konsentrasi gas $\mathrm{SO}_{2}$ per variasi bukaan ventilasi dengan Baku mutunya dapat dilihat pada grafik pada Gambar 4 berikut ini.

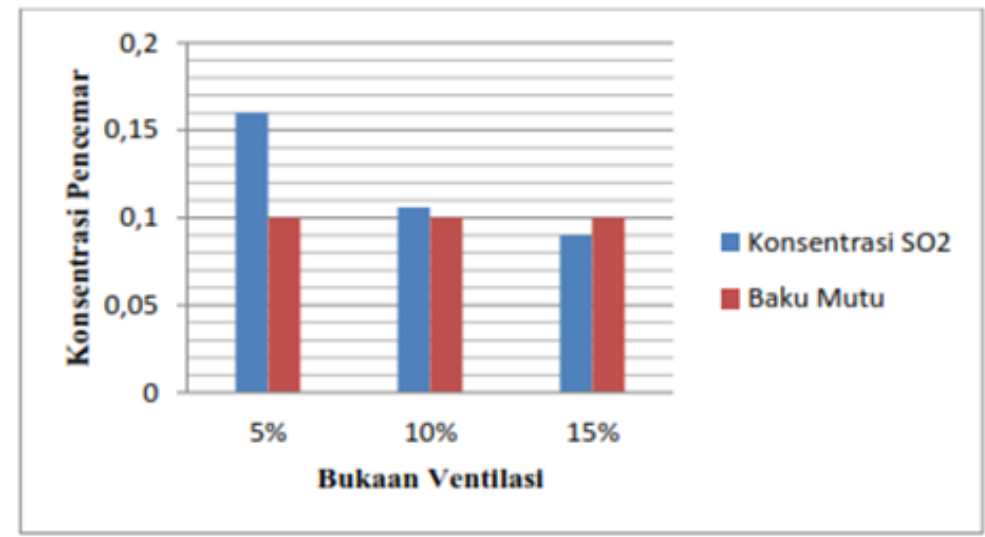

Gambar 4. Perbandingan Konsentrasi Gas $\mathrm{SO}_{2}$ dengan Baku Mutu pada Variasi Bukaan Ventilasi. 
Dari hasil pengukuran dapat diketahui adanya hubungan antara pertambahan luas bukaan ventilasi dengan pencemar yang dihasilkan dari pembakaran tandan kosong sawit, dimana pertambahan luas bukaan ventilasi akan menurunkankonsentrasi pencemar yang dihasilkan. Hal ini dikarenakan bukaan ventilasi dalam sebuah ruangan sangat mempengaruhi kualitas udara dalam sebuah ruangan (indoor air quality) tersebut dimana ventilasi berhubungan dengan sirkulasi udaradidalam ruangan tersebut. Adanya ventilasi udara bertujuan untuk pergantian udara dan oksigen didalam ruangan, dengan dilakukannya pertambahan luas permukaan ventilasi udara maka udara yang ada didalam ruangan akan lebih cepat berputar dan berganti dengan udara yang ada diluarruangan (Kurniawan,2016). Sirkulasi udara yang baik dalam ruangan tersebut juga akan membantu pensuplaian Oksigen yang dibutuhkan sehingga diharapkan pembakaran sempurna saat berlangsungnya pembakaran dari Briket Tandan Kosong Sawit.

\section{SIMPULAN}

1. Pada penelitian ini konsentrasi pencemar gas $\mathrm{SO}_{2}$ yang dihasilkan dari pembakaran briket tandan kosong sawit bervariasi pada setiap bukaan ventilasi udara, yaitu $0.16 \mathrm{ppm}$ untuk bukaan 5\%, 0,106 ppm untuk bukaam 10\% dan 0,09 ppm untuk bukaan ventilasi $15 \%$.

2. Kandungan $\mathrm{SO}_{2}$ dari pembakaran briket tandan kosong sawit berada di bawah standar baku mutu PerMenKes RI No. 1077 tahun 2011 tentang Pedoman Penyehatan Udara dalam Ruangan dengan kondisi ruangan yang memiliki ventilasi $15 \%$ dari luar lantai rumah.

\section{DAFTAR PUSTAKA}

April (2013), Penyerapan gas CO hasil pembakaran sampah menggunakan Sorbent termodifikasi dalam reactor Fixed Bed.

Boguski, T. (2019). Environmental Science and Technology Briefs for Citizens. USA : Kansas State University.

Geombira, F., Nazir A., Husan, A., \& Ihsan, T. (2019). Analisa Konsentrasi PM2,5, CO dan $\mathrm{CO}_{2}$ di dalam Ruangan Akibat Pennggunaan Kompor Biomassa Berbahan Bakar Briket

Hadi, A dan Nurjaman, A. (2017). Verifikasi Metode Pengujian Udara Ambien dan Emisi Mendukung Penerapan ISO/IEC 17025 Q2017). Bogor: IPB-Press

Khoiri A, E Annom dan Wawan (2013). Perubahan Sifat Fisik Berbagai Jenis Tanah di Bawah Tegakan Kelapa Sawit yang Diaplikasikan Tandan Kosong Kelapa Sawit (TKKS) di PT. Salim Ivomas Pratama J. Online. Mahasiswa.

Kurniawan, Y (2016). Studi Kinerja Ventilasi Mekanik Insuflasi untuk Kualitas Udara dalam Bangunan. Jurnal Teknik Pendingin dan Tata Udara. Vol. II Nomor 1. Politeknik Negeri Indramayu..

Mardiansyah. (2015). Pembuatan Briket Arang Tandan Kosong Kelapa Sawit (TKKS) dan Cangkang Kelapa Sawit (CKS) dengan Penambahan Kotoran Sapi.

PERMENKES RI NOMOR 1077/MENKES/PER/V/2011 tentang Pedoman Penyehatan Udara dalam Ruang Rumah. 
Pusat Statistika Indonesia. (2018). Statistik Kelapa Sawit Indonesia tahun 2018. Jakarta Pusat : Badan Pusat Statistik.

Ronaldo, N. (2020). Pemanfaatan Tandan Kosong Sawit dan Spent Bleaching Earth (SBE) sebagai Bahan Baku Pembuatan Briket dengan Variasi Ukuran Partikel. Skripsi Teknik Lingkungan. Fakultas Teknik. Universitas Riau.

Sinta (2020). Pemanfaatan Tandan Kosong Sawit dan Spent Bleaching Earth (SBE) sebagai Bahan Baku Pembuatan Briket dengan Variasi Tekanan. Skripsi. Teknik Lingkungan. Fakultas Teknik. Universitas Riau.

SNI 19-7119.7.2005 Udara ambien - Bagian 7 : Cara Uji Kadar Sulfur Dioksida $\left(\mathrm{SO}_{2}\right)$ dengan metoda pararosanilin menggunakan Spektrofotometer. Panitia Teknis Sistem Manajeman Lingkungan (Paniitia Teknis 207S).

SNI (2000). Brket Arang Kayu. SNI 01-6235-2000. Departemen Teknik Pertanian, Jakarta.

Sukma, S.A. (2020). Pemanfaatan Tandan Kosong Sawit dan Spent Bleaching Earth (SBE) sebagai Bahan Baju Pembuatan Briket dengan Variasi Konsentrasi Perekat. Skripsi. Teknik Lingkungan. Fakultas Teknik.Universitas Riau. Pekanbaru.

Tempurung Kelapa dan Briket Kayu Bakar. Jurnal Dampak, 16(1), 42-50.

Ullyta A, Mahbub I, Nasution, H. (2017). Dampak Lama Aplikasi Mulsa TKKS Terhadap Sifat Tanah dan Penangkaran Kelapa Sawit di Kebun PT. Sari Aditya Loka 1 Kecamatan Air Hitam Kabupaten Sarolangun. Jurnal Agroekoteknologi. Fakultas Pertanian. Universitas Jambi.

[USDA] United States Department of Agriculture. (2017). Oil seeds: world market and trade. Washington (US): Foreign Agricultural Service United States Department of Agriculture.

Yudanto A. dan Kusumaningrum, K. (2008). Pembuatan Briket Bioarang Dari Arang Serbuk Gergaji Kayu Jati. Semarang : Jurusan Teknik Kimia, Fakultas Teknik, Universitas Diponegoro 